\title{
An Investigation of Growth Mechanism of Coal Derived Graphene Films
}

\author{
Santosh H. Vijapur ${ }^{1}$, Dan Wang ${ }^{1}$, David C. Ingram ${ }^{2}$, and Gerardine G. Botte ${ }^{1 *}$ \\ ${ }^{1}$ Center for Electrochemical Engineering Research, \\ Department of Chemical and Biomolecular Engineering, Ohio University \\ ${ }^{2}$ Edwards Accelerator Laboratory, \\ Department of Physics and Astronomy, Ohio University
}

182 Mill Street

Ohio University

Athens, $\mathrm{OH} 45701$

Phone: 740-593-9670

Fax: 740-593-0873

Email: botte@ohio.edu

\begin{abstract}
A revised research paper submitted to Materials Today Communications for consideration for publication
\end{abstract}

${ }^{*}$ Corresponding Author. Tel.: 1-740-593-9670, fax: 1-740-593-0873. Email: botte@ ohio.edu 


\begin{abstract}
The growth mechanism of coal derived graphene films synthesized via chemical vapor deposition on copper substrates was investigated utilizing Raman spectroscopy, X-ray photoelectron spectroscopy, selected area electron diffraction, optical microscopy, and gas chromatography. The synthesis of coal derived graphene films is a two-step process, wherein the copper in annealed followed by flash pyrolysis of coal under hydrogen environment. The growth mechanism involves a copper catalyzed reaction to produce a carbon film within the first few minutes of synthesis, followed by a hydrogen catalyzed graphitization of the underlying carbon film to form graphene domains which merge together to form graphene films.
\end{abstract}




\section{Introduction:}

The discovery of graphene has created an increasing interest in developing an efficient synthesis route for high quality and large-scale production opening a new wave of research in targeting its use in diverse applications [1-8]. Chemical vapor deposition (CVD) has been demonstrated as a promising technique for high quality, large area, transparent, and scalable graphene synthesis [9-11]. Hydrocarbons, which includes gases (such as methane, ethylene, acetylene, etc.) [10, 12], solids (such as polymethyl methacrylate, polystyrene, etc.) [13, 14], and liquids (such as methanol, ethanol, benzene, etc.) [13, 15], are utilized as carbon sources for CVD synthesis of graphene. These carbon sources are unreliable for large-scale graphene production due to their limited supplies and high cost. Efforts are directed towards utilizing alternate carbon sources, which are inexpensive and readily available. Biomass waste and food waste showed the potential for graphene production at low cost $[16,17]$. Initially, we demonstrated the use of coal as a carbon source to grow amorphous carbon thin films [18]. We further synthesized graphene films from coal and utilized the coal derived graphene films for battery applications $[19,20]$. Coal is a naturally abundant inexpensive carbon source, which shows great potential for sustainable, low cost, and scalable synthesis of graphene films.

Studies of the growth mechanism of graphene are critical to tailor the graphene films as desired for various applications. The graphene growth mechanism is influenced by not only the synthesis conditions such as temperature, pressure, time, etc.; but also by the solubility of carbon on the metal substrate $[12,21-27]$. The low carbon solubility on the copper substrate has been demonstrated to be ideal for monolayer synthesis of graphene [12, 22]. Previous studies of the graphene growth mechanism directly on copper substrates focused on the formation of monolayer graphene films utilizing pure hydrocarbon sources such as methane, ethylene, etc. 
$[12,21-24]$. It has been demonstrated that the mechanism involves copper catalyzed surface adsorption of carbon species from the pure hydrocarbon source, which undergoes nucleation to form graphene domains. These graphene domains grow and merge together to form a monolayer graphene film on the copper substrate $[22,24]$. This surface mediated growth mechanism is thought to be self-limiting, and is attributed to the low solubility of carbon species on the copper substrate $[12,22]$. However, various studies have demonstrated a change in graphene growth kinetics depending on the growth conditions leading to formation of bilayer or multilayer graphene films $[25,28,29]$. This confirms the self-limiting graphene growth mechanism does not hold for all the growth conditions.

Furthermore, there has been little focus on investigating the graphene growth mechanism using solid carbon sources such as coal. An understanding of the graphene growth mechanism using coal will have a significant impact on the optimization of the synthesis conditions, economics, and environment during the efficient scale up of the process. Unlike pure hydrocarbon gases, coal is a complex carbon source which when pyrolyzed releases a mixture of various gases including hydrocarbons with different molecular weights. Moreover, the partial pressure of gaseous hydrocarbons presumably influences the graphene growth $[27,28,30]$ is challenging to control while utilizing a complex solid carbon source such as coal. Consequently, it is essential to elucidate the carbon nucleation, growth of domains, and coal pyrolysis products to better understand the growth mechanism of coal derived graphene films.

Within this context, the objective of the present work is to investigate the growth mechanism of coal derived graphene films, which will facilitate future production of high quality graphene films from various types of coal (such as anthracite, bituminous, etc.) as carbon source. Further, characterization of these graphene domains and the graphene films using optical 
microscopy, transmission electron microscopy (TEM), selected area electron diffraction (SAED), Raman spectroscopy, and X-ray photoelectron spectroscopy (XPS) will assist in predicting a growth model for the coal derived graphene films.

\section{Experimental:}

\subsection{Chemicals and materials}

The coal used for the experimental work was Wyodak coal (Wyodak coal seam, Wyoming), a sub-bituminous type, which was purchased from the Penn state coal bank. The datasheet provided by the Penn state coal bank reported the elemental analysis of Wyodak coal as - carbon (69.74\%), hydrogen (5.55\%), nitrogen $(0.94 \%)$, organic sulfur $(0.35 \%)$, oxygen (14.83\%), and mineral matter $(8.59 \%)$ content.

Copper foils $(99.8 \%, 0.025 \mathrm{~mm}$ thickness) obtained from Alfa Aesar were used as substrate for graphene synthesis. Acetone (> 99\%) used for rinsing the copper foils was purchased from Fisher Scientific. Cupric sulfate (> 95\%), and Hydrochloric acid (6 N) used for preparation of Marbles reagent were also procured from Fisher Scientific. Silicon wafers (SSP $0.025 \mathrm{~mm}$ Virginia Semiconductor Inc.) were used as substrate to transfer the graphene films for characterization. Copper grids (PELCO® Center-Marked Grids, 300 mesh, $3.0 \mathrm{~mm}$ O.D.) and lacey carbon grids (300 mesh, Copper) purchased from Ted Pella were used for transmission electron microscopy (TEM) characterization. 5 L Tedlar sampling bags with SS fittings were purchased from SKC Inc. for gas collection during the in-situ and flash coal pyrolysis process.

\subsection{Sample preparation and synthesis}

The sample preparation and synthesis were performed using the experimental procedure and setup described in our previous work [19]. Coal $(10 \mathrm{mg})$ was loaded on one quartz boat and 
placed outside the heat zone in a tubular furnace. Copper foil was placed on another quartz boat and placed inside the heat zone in the furnace. The furnace was evacuated with a vacuum pump and backfilled with hydrogen. The furnace was ramped to the desired synthesis temperature for annealing the copper followed by flash coal pyrolysis for the growth of graphene on the copper substrate. The carbon/graphene films were synthesized at various temperatures/time as shown in table 1 . The dimensions of the tubular oven affect the synthesis time and the gas flow rates. The objective of this work is to provide a better understanding of the growth mechanism and not to optimize the synthesis conditions.

Table 1: Synthesis conditions (temperature and time) for the growth of carbon films.

\begin{tabular}{|c|c|c|c|c|c|}
\hline $\begin{array}{c}\text { Synthesis } \\
\text { temperature } \\
\left({ }^{\circ} \mathbf{C}\right)\end{array}$ & $\begin{array}{c}\text { Synthesis } \\
\text { time } \\
\text { (min) }\end{array}$ & $\begin{array}{l}\text { Material } \\
\text { obtained }\end{array}$ & $\begin{array}{c}\text { Synthesis } \\
\text { temperature } \\
\left({ }^{\circ} \mathrm{C}\right)\end{array}$ & $\begin{array}{l}\text { Synthesis } \\
\text { time } \\
\text { (min) }\end{array}$ & $\begin{array}{l}\text { Material } \\
\text { obtained }\end{array}$ \\
\hline 455 & 30 & C film & 1055 & 6 & hybrid C film \\
\hline 655 & 30 & C film & 1055 & 12 & hybrid C film \\
\hline 855 & 30 & C film & 1055 & 18 & Graphene \\
\hline 955 & 30 & C film & 1055 & 24 & Graphene \\
\hline 1000 & 30 & C film & 1055 & 30 & Graphene \\
\hline 1055 & 30 & Graphene & 1055 & 45 & Graphene \\
\hline
\end{tabular}

The copper foils were then dropped to float in a petri dish containing Marble's reagent (10 g $\mathrm{CuSO}_{4}, 50 \mathrm{ml} \mathrm{HCl}, 50 \mathrm{ml}$ deionized -DI- water) until the copper dissolved in $\sim 2-3 \mathrm{~h}$ and the synthesized carbon films were observed to float in the solution. The carbon films were then lifted 
using a clean glass slide and transferred to a petri dish containing DI water. The process was repeated twice to remove the contaminants from the surface of the carbon films before finally transferring onto desired substrates such as silicon wafer, TEM grids, etc. for further characterization. The transfer process is also described in our previous work [19].

\subsection{Gas collection}

The gases released as coal pyrolysis products were collected in a $5 \mathrm{~L}$ Tedlar gas sampling bag connected at the exhaust of the tubular furnace. Prior to the pyrolysis, the sampling bag was purged with helium and hydrogen three times each to remove excess air from the sampling bag.

\subsection{Graphene domain visualization}

In order to make graphene domains optically visible, the copper foils with the graphene films were placed on a hot plate at $100{ }^{\circ} \mathrm{C}$ for $1 \mathrm{~min}$. The area with the presence of graphene domains remains unaffected, whereas other areas of the copper foil are oxidized [31-33]. The colour contrast between the oxidized region and non-oxidized region was visible under Alicona® InfiniteFocus Optical Microscope (IFM).

\subsection{Physical characterization:}

Raman spectroscopy/mapping is a powerful tool to investigate the structural properties and growth of graphene films [34, 35]. The carbon/graphene films synthesized at different temperatures/times were transferred onto silicon wafers for performing Raman spectroscopy/mapping. The Raman spectra of the carbon/graphene films were obtained using a Bruker Senterra Raman spectrometer. A 20X objective lens was used to acquire Raman spectra using an argon laser $(\lambda=532 \mathrm{~nm})$ with $20 \mathrm{~mW}$ power, resolution range of $3-5 \mathrm{~cm}^{-1}$ and integration time of $20 \mathrm{~s}$; whereas Raman mapping measurements were obtained utilizing $2 \mathrm{~mW}$ power, 
resolution range of $9-15 \mathrm{~cm}^{-1}$ and integration time of $10 \mathrm{~s}$. Raman mapping over $100 \times 100 \mu \mathrm{m}^{2}$ area with step size of $5 \mu \mathrm{m}$ was selected for measurements. Transmission electron microscopy (TEM) images and the selected area electron diffraction (SAED) of the carbon/graphene films were obtained using the JEM 2100F Transmission Electron Microscope (TEM). The X-ray photoelectron spectroscopy (XPS) analysis of the various carbon/graphene films were conducted using Kratos XSAM 800 electron spectrometer with a 1484 kaAl X-ray source utilizing 120 W power and pass energy of $40 \mathrm{eV}$. The images of graphene domains on the copper foil were attained utilizing an Alicona ${ }^{\circledR}$ InfiniteFocus Optical Microscope (IFM). The images were then analyzed using ImageJ software. The collected gases were analyzed using Thermo Scientific Gas Chromatograph.

\section{Results and Discussion:}

The coal derived graphene films were synthesized using low pressure CVD at $1055^{\circ} \mathrm{C}$ and 30 min synthesis conditions as demonstrated in previous work [19]. Raman spectrum of the coal derived graphene films (figure 1a) reveals D band at $1350 \mathrm{~cm}^{-1}, \mathrm{G}$ band at $1575 \mathrm{~cm}^{-1}$, and $2 \mathrm{D}$ band at $2700 \mathrm{~cm}^{-1}$. The presence of $\mathrm{D}$ band in the graphene films is a mode in Raman spectra of first order originating from the disorder and defects such as point defects, subdomain boundaries, etc. $[11,25,34-36]$. These can be due to the breaking of hexagonal graphene structure caused by other functional groups such as $\mathrm{C}-\mathrm{O}, \mathrm{C}=\mathrm{O}$, etc. or by the $\mathrm{sp}^{3}$ carbon $[14,37$ 39]. According to our synthesis method (Section 2.2), the solid coal sample is fed into the tubular oven; therefore, it is hypothesized that gaseous mixture generated from the in-situ pyrolysis of coal can contain the $\mathrm{C}-\mathrm{O}$ groups that lead to defects in the synthesized graphene. The $\mathrm{G}$ band in the coal derived graphene film arises due to the tangential vibrations associated with the $\mathrm{sp}^{2}$ bonded carbon atoms $[25,34,35]$. Another band at $\sim 2700 \mathrm{~cm}^{-1}$ is designated as $2 \mathrm{D}$ band, which 
is a mode in Raman spectra of second order and is associated with layers in the graphene films $[25,34,35]$. These bands in the Raman spectra are used to identify the quality and the number of layers associated with the graphene films [34, 35]. The relative intensity of $2 \mathrm{D} / \mathrm{G}$ is $\sim 1$ and the FWHM of the 2D peak is $\sim 31 \mathrm{~cm}^{-1}$, which demonstrates formation of bi-layer graphene films $[11,12,14,25,34,40]$.
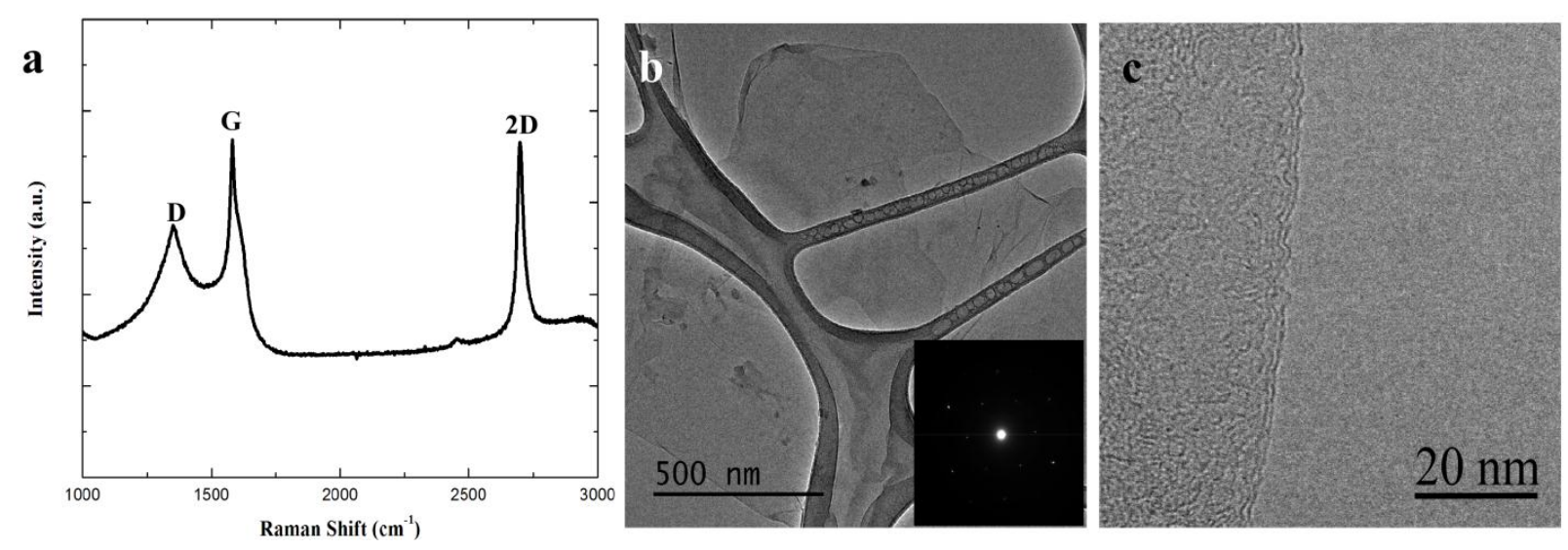

Figure 1. (a) Raman spectra of coal derived graphene film synthesized at $1055^{\circ} \mathrm{C}$ and $30 \mathrm{~min}$ exhibiting D, G, and 2D band. (b) Large area of coal derived graphene films on TEM grid showing wrinkles, overlapping, and backfolding; Inset: SAED with six diffraction spots demonstrating crystalline nature of coal derived graphene film. (c) High magnification TEM image with the edge of the coal derived graphene film exhibiting bi-layers.

TEM image in figure $1 \mathrm{~b}$ illustrates large area of the graphene film on the TEM grid with wrinkles, back folding, and overlapping introduced due to the transfer process. The selected area electron diffraction (SAED - inset in figure 1b) reveals the six diffraction spots depicting the hexagonal diffraction pattern and the crystalline nature of the coal derived graphene films. The edge of the graphene film (TEM image in figure 1c) reveals the bi-layers of the coal derived graphene films, which is in agreement with the Raman analysis. In addition, the XPS survey spectrum of graphene film synthesized at $1055{ }^{\circ} \mathrm{C}$ and $30 \mathrm{~min}$ (Figure $\mathrm{S} 1$ - see supporting 
information) reveals the presence of carbon, oxygen, and copper (from substrate). The XPS survey did not show any other impurities present in the graphene films.

In order to investigate the growth mechanism of coal derived graphene films, the synthesis was performed at different temperatures/times. Initially, the synthesis was conducted for 30 minutes at different temperatures as mentioned in Table 1. Raman spectra (figure 2) of the low temperature $\left(455^{\circ} \mathrm{C}, 655^{\circ} \mathrm{C}\right.$, and $\left.855^{\circ} \mathrm{C}\right)$ synthesized films exhibit only D band and $\mathrm{G}$ band with broad shoulders demonstrating their amorphous nature [41, 42]. Increase in synthesis temperature to $955^{\circ} \mathrm{C}$ and $1000{ }^{\circ} \mathrm{C}$ also yielded only carbon films exhibiting $\mathrm{D}$ band and $\mathrm{G}$ band in the Raman spectra as seen in supporting information figure S2. As the synthesis temperature is further increased to $1055^{\circ} \mathrm{C}$, a 2D peak is also detected along with $\mathrm{D}$ and $\mathrm{G}$ bands, confirming the formation of the graphene film. The 2D/G intensity and FWHM revealed formation of a bilayer graphene film. The presence of a D peak in the Raman spectra of a graphene film is the result of defects and disorder due to $\mathrm{C}-\mathrm{O}, \mathrm{C}=\mathrm{O}, \mathrm{sp}^{3}$ carbon, etc. within the graphene network of $\mathrm{sp}^{2}$ carbon. As a comparison, the Raman spectra of raw coal is also included (figure 2), which shows a broad D band at $1365 \mathrm{~cm}^{-1}$ and $\mathrm{G}$ band at $1575 \mathrm{~cm}^{-1}$ indicating the amorphous nature of the coal [41]. 


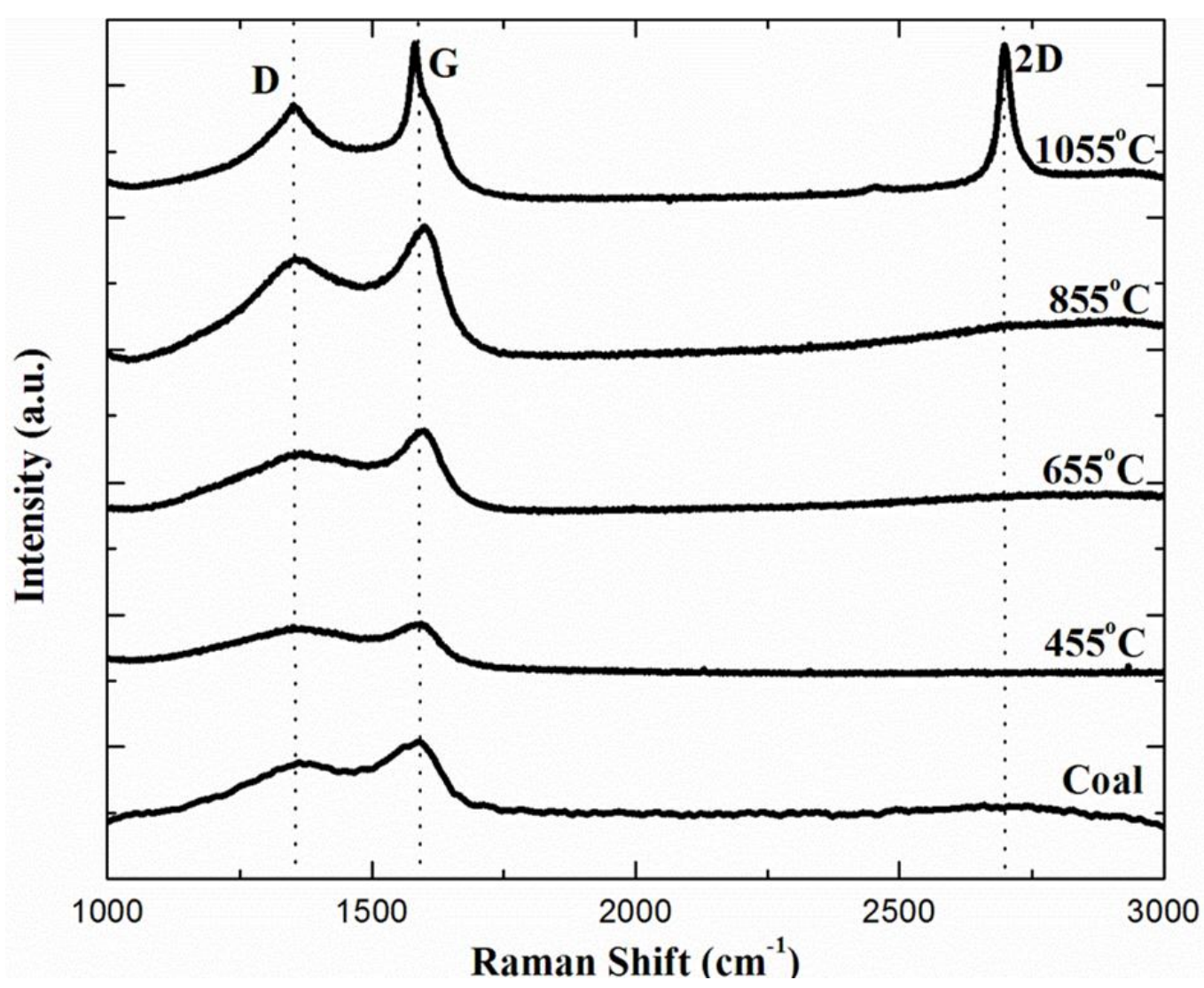

Figure 2. Raman spectra of films synthesized at different temperatures and 30 min synthesis time demonstrating formation of graphene films when the temperature is increased to $1055^{\circ} \mathrm{C}$.

Further, Raman mapping was conducted in order to validate the results of Raman measurements over large areas of the carbon films. A $100 \times 100 \mu \mathrm{m}^{2}$ area was selected on each sample for the mapping. The results were analyzed in terms of 2D band intensity only, since the interest was to detect the temperature required for graphene formation. Figure 3 shows the 2D band intensity map area of films synthesized at different temperatures and 30 min synthesis time. It can be observed that the 2D peak intensity is close to zero for films synthesized at $455{ }^{\circ} \mathrm{C}$ (figure 3a), $655^{\circ} \mathrm{C}$ (figure 3b) and $855^{\circ} \mathrm{C}$ (figure 3c) indicating no formation of graphene films. However, the 2D peak intensity is dominant over large area of films synthesized at $1055{ }^{\circ} \mathrm{C}$ (figure 3d) revealing the continuous and large area graphene formation. Raman mapping 
(measurements with respect to the 2D peak intensity) was also conducted on the replicate samples synthesized at different temperatures in order to determine the uniformity of the films. Figure S3 (see supporting information) shows that the 2D peak intensity is negligible for films synthesized at $455^{\circ} \mathrm{C}, 655^{\circ} \mathrm{C}$, and $855^{\circ} \mathrm{C}$ without significant variation. However, the 2D map shows high intensity and uniformity for the replicates synthesized at $1055^{\circ} \mathrm{C}$.
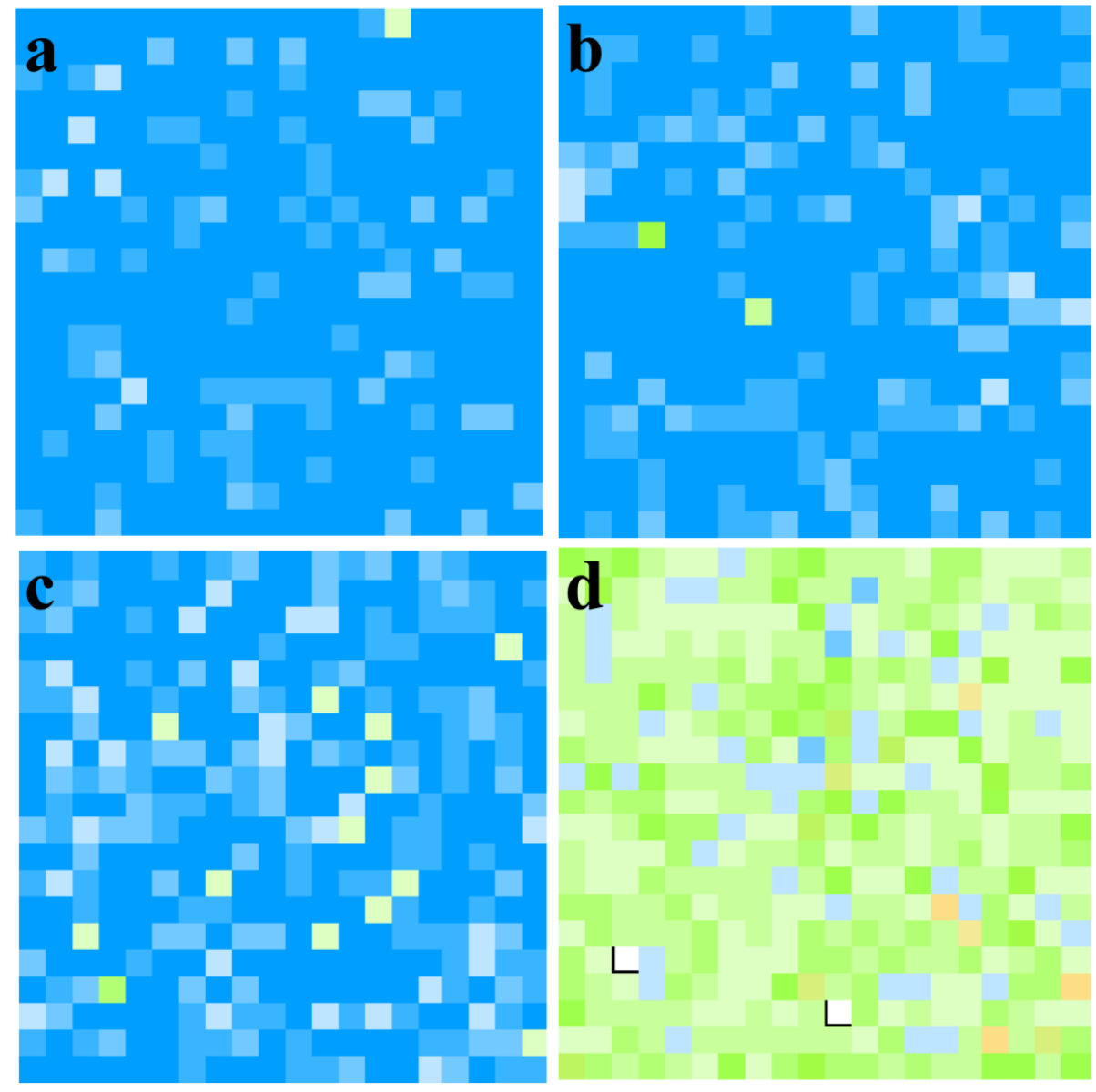

3000

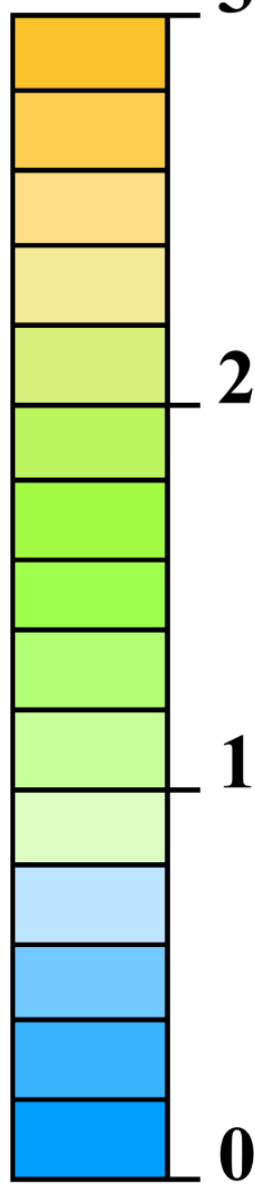

2000

1000

Figure 3. Raman map measurements showing the $2 \mathrm{D}$ band intensity over $100 \times 100 \mu \mathrm{m}^{2}$ area of films synthesized at $455^{\circ} \mathrm{C}$ (a), $655^{\circ} \mathrm{C}(\mathrm{b}), 855^{\circ} \mathrm{C}$ (c), and $1055^{\circ} \mathrm{C}$ (d) demonstrating the presence of $2 \mathrm{D}$ band over large area for films produced at $1055^{\circ} \mathrm{C}$. 
X-ray photoelectron spectroscopy (XPS) is an ideal technique not only used to determine the elemental composition of monolayer-scale carbonaceous materials, but also to provide information regarding the chemical composition [43, 44]. Therefore, XPS was employed to detect the core level C1s carbon spectra directly on the copper surface. Figure 4 represents the C1s spectra of the carbon/graphene films synthesized at different temperatures and $30 \mathrm{~min}$ synthesis time. The $\mathrm{C} 1 \mathrm{~s}$ spectra of the various carbon films were found to be around $284 \mathrm{eV}$ $286 \mathrm{eV}$. The background of the peaks was subtracted using the nine point Shirley background and deconvoluted using a Gaussian-Lorentzian fit. The C1s spectra for the various films were deconvoluted into four peaks. The decomposed peaks and their corresponding components are: $\mathrm{sp}^{2}$ graphitic carbon $(284.5 \mathrm{eV}), \mathrm{sp}^{3}$ amorphous carbon $(285.5 \mathrm{eV}), \mathrm{C}-\mathrm{O}(286.5 \mathrm{eV})$, and $\mathrm{O}-\mathrm{C}=\mathrm{O}$ $(288.5 \mathrm{eV})$ [21, 43-48]. The oxygen related components and the $\mathrm{sp}^{3}$ carbon are dominant and have high intensity for low temperature films (figure $4 \mathrm{a}-455{ }^{\circ} \mathrm{C}$, and $4 \mathrm{~b}-655{ }^{\circ} \mathrm{C}$ ). As the temperature is increased see figure $4 \mathrm{c}\left(855^{\circ} \mathrm{C}\right)$ and figure $4 \mathrm{~d}\left(1055^{\circ} \mathrm{C}\right)$, the peak intensity of the oxygen related components and the $\mathrm{sp}^{3}$ carbon decreases and is found to be lowest for the graphene films synthesized at highest temperature (figure $4 \mathrm{~d}-1055^{\circ} \mathrm{C}$ ). Conversely, the peak representing $\mathrm{sp}^{2}$ carbon has low intensity for low temperature films $\left(455^{\circ} \mathrm{C}\right.$ and $\left.655^{\circ} \mathrm{C}\right)$. The peak intensity of $\mathrm{sp}^{2}$ carbon increases with temperature and shows the highest concentration for graphene films.

The XPS analysis is consistent with the results from Raman measurements, indicating that the presence of $\mathrm{sp}^{3}$ carbon and various carbon-oxygen functional groups within the graphene network is correlated with defects in the graphene films. The difference in concentrations of $\mathrm{sp}^{2}$ carbon, $\mathrm{sp}^{3}$ carbon, and oxygen related components, follows the phase change from amorphous (low temperature films $-455^{\circ} \mathrm{C}, 655^{\circ} \mathrm{C}$, and $855^{\circ} \mathrm{C}$ ) to crystalline (high temperature films - 
$\left.1055^{\circ} \mathrm{C}\right)$. The peaks corresponding to the oxygen components are calculated to occupy an area of $\sim 20 \%$ of the total area of the carbon C1s spectra of the graphene films. This can be attributed to various reasons such as oxidation of the copper foil, adsorption of air on the graphene films, or the oxidation of carbon atoms near the domain boundaries [43-45]. Furthermore, the gaseous mixture generated during the flash pyrolysis of coal contain C-O groups that can also induce defects in the graphene films.
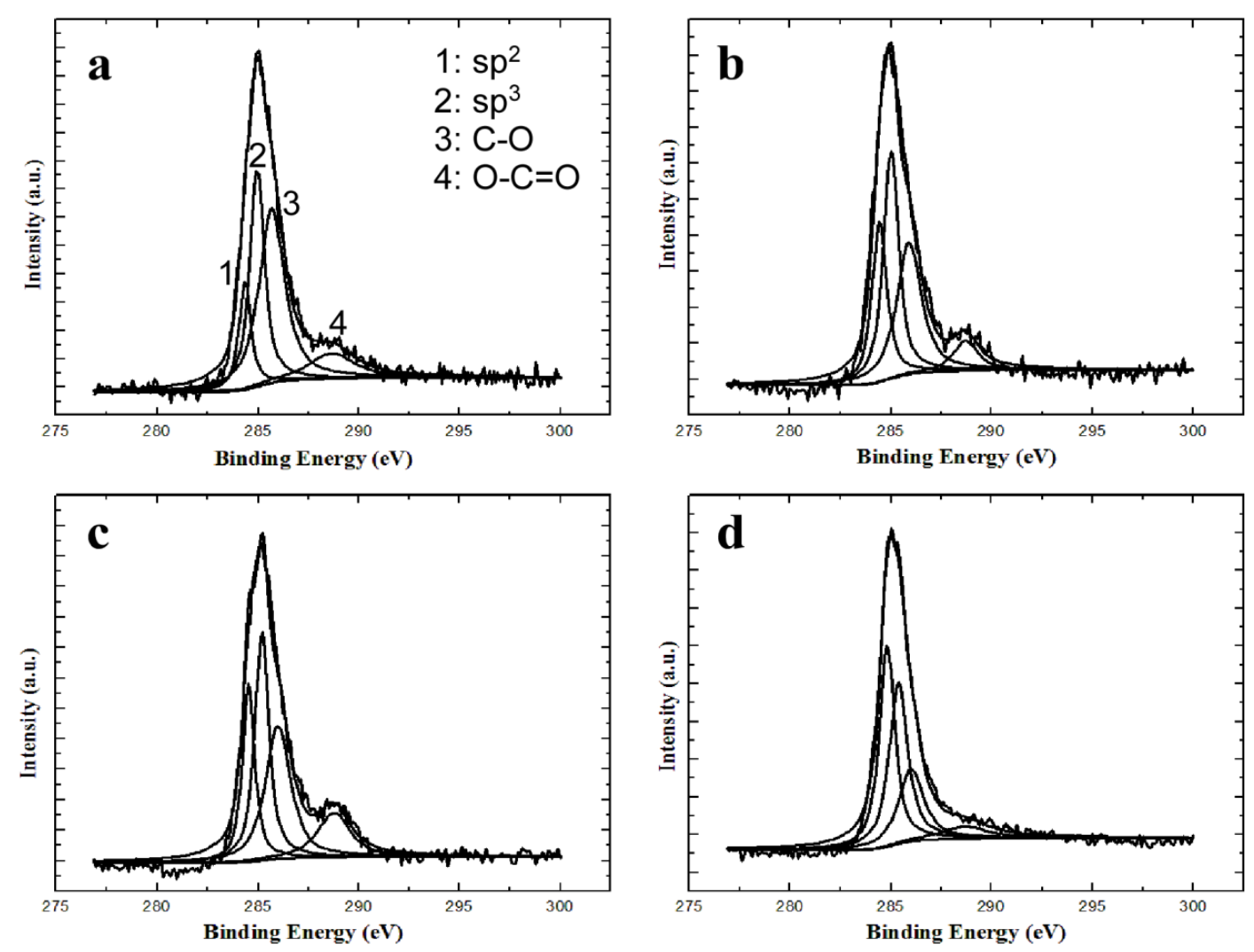

Figure 4. XPS C1s spectra of carbon films synthesized at $455^{\circ} \mathrm{C}(\mathrm{a}), 655^{\circ} \mathrm{C}(\mathrm{b}), 855^{\circ} \mathrm{C}$ (c), and $1055^{\circ} \mathrm{C}(\mathrm{d})$ and 30 min. synthesis time. $\mathrm{C} 1 \mathrm{~s}$ spectra of the graphene films $\left(1055^{\circ} \mathrm{C}\right)$ show low amounts of $\mathrm{sp}^{3}$ carbon and oxygen related components as compared to carbon films synthesized at low temperatures $\left(455^{\circ} \mathrm{C}, 655^{\circ} \mathrm{C}\right.$, and $\left.855^{\circ} \mathrm{C}\right)$.

Selected area electron diffraction (SAED) was conducted on the films synthesized at 
different temperatures and 30 min synthesis time for investigating the nature and phase change. Figure 5 a-d shows the SAED pattern of the synthesized films. The SAED reveals an intense ring without any presence of diffraction spots for low temperature films (figure $5 \mathrm{a}-455^{\circ} \mathrm{C}$, and $5 \mathrm{~b}$ $655^{\circ} \mathrm{C}$ ), indicating their amorphous nature. The SAED pattern of films synthesized at $855^{\circ} \mathrm{C}$ (figure 5c) shows a combination of diffraction spots and intense rings indicating a hybrid structure of amorphous and crystalline carbon. Similar SAED pattern was observed by Cui et al., for their low temperature synthesized hybrid films [49]. However, only hexagonal diffraction spots are observed for the graphene films (figure $5 \mathrm{~d}-1055^{\circ} \mathrm{C}$ ), demonstrating their crystalline nature. The SAED characterization is in agreement with the Raman and XPS measurements. 

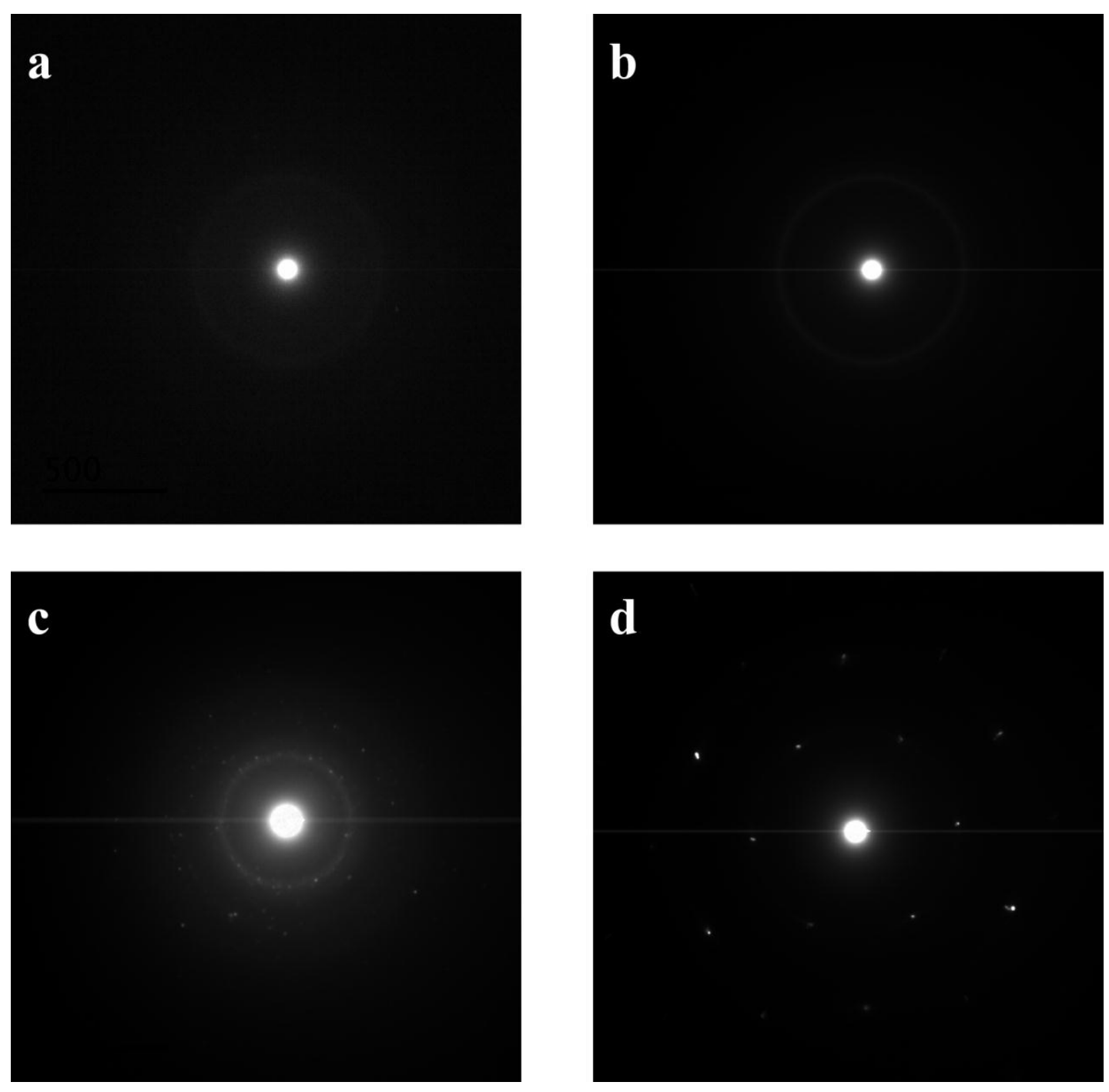

Figure 5. Selected area electron diffraction of films synthesized at $455{ }^{\circ} \mathrm{C}$ (a), $655{ }^{\circ} \mathrm{C}$ (b), 855

${ }^{\circ} \mathrm{C}(\mathrm{c})$, and $1055{ }^{\circ} \mathrm{C}(\mathrm{d})$. Amorphous rings present for low temperature films $\left(455{ }^{\circ} \mathrm{C}\right.$ and 655 ${ }^{\circ} \mathrm{C}$ ), a hybrid film is synthesized at $855^{\circ} \mathrm{C}$, and crystalline graphene films is formed at $1055^{\circ} \mathrm{C}$.

After investigating the synthesis temperature required for graphene formation, it was essential to observe the growth and evolution of the graphene films. This was achieved by increasing the synthesis time from 6 min up to 45 min. Figure 6 shows the Raman spectra of the graphene films synthesized at $1055^{\circ} \mathrm{C}$ and different synthesis times. The $2 \mathrm{D}$ peak intensity is negligible for films synthesized at $6 \mathrm{~min}$. However, as the synthesis time is increased the 2D 
peak becomes sharper and peak intensity increases. This behaviour is caused by the increase in graphitization/crystallization of amorphous carbon films and increase in the size of graphene domain with corresponding increase in synthesis time. In order to verify the size of graphene domain optical microscopy was utilized, which is discussed in the later part.

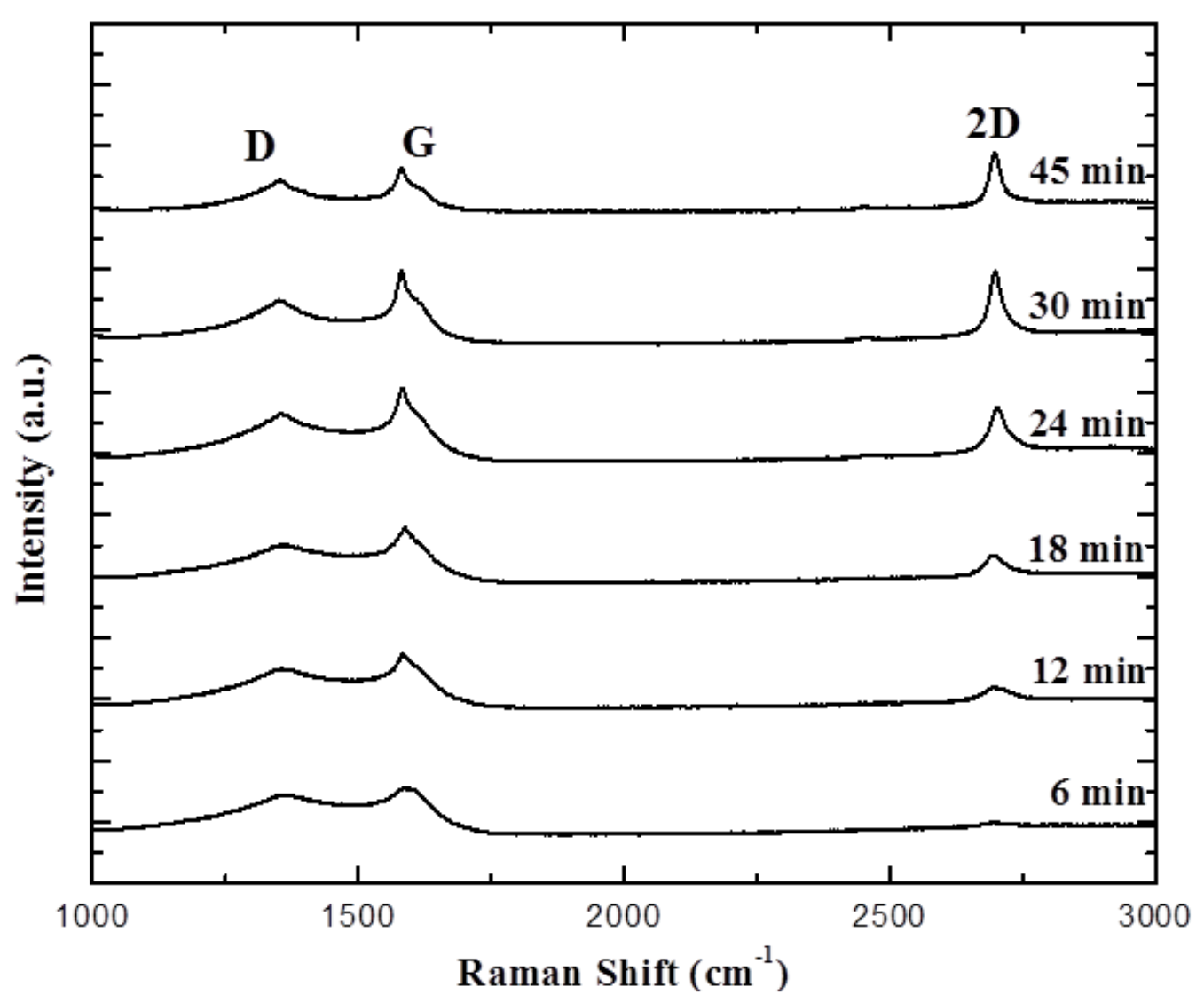

Figure 6. Raman spectra of films synthesized at $1055{ }^{\circ} \mathrm{C}$ and different time demonstrating graphitization and increase in domain size as synthesis time is increased.

The evolution of the 2D band is also evidenced from the map measurements (figure 7a-e) demonstrating the intensity of $2 \mathrm{D} / \mathrm{G}$ ratio over $100 \times 100 \mu \mathrm{m}^{2}$ area of the graphene films. The intensity of $2 \mathrm{D} / \mathrm{G}$ ratio is negligible for films synthesized at $6 \mathrm{~min}$ (figure $7 \mathrm{a}$ ). However, with progressively longer time duration the $2 \mathrm{D} / \mathrm{G}$ intensity ratio increases from $\leq 0.4$ for $12 \mathrm{~min}$ (figure 7b), $\leq 0.6$ for $18 \min$ (figure 7c), $\leq 0.8$ for $24 \min$ (figure $7 d$ ) up to $\geq 1$ for $30 \mathrm{~min}$ and 
45min synthesis (figure $7 \mathrm{e}$ and $\mathrm{f}$ ). The $2 \mathrm{D} / \mathrm{G}$ map results indicate that a large fraction of the area is covered with bi-layer graphene films for $1055^{\circ} \mathrm{C}$ and $30 / 45$ min synthesis. Raman mapping was also conducted on the replicate samples to validate if the $2 \mathrm{D} / \mathrm{G}$ intensity ratio is uniform and repeatable across the replicates. The $2 \mathrm{D} / \mathrm{G}$ intensity ratio among the replicate samples increases with increase in synthesis time without significant variation as shown in figure S4 (see supporting information).
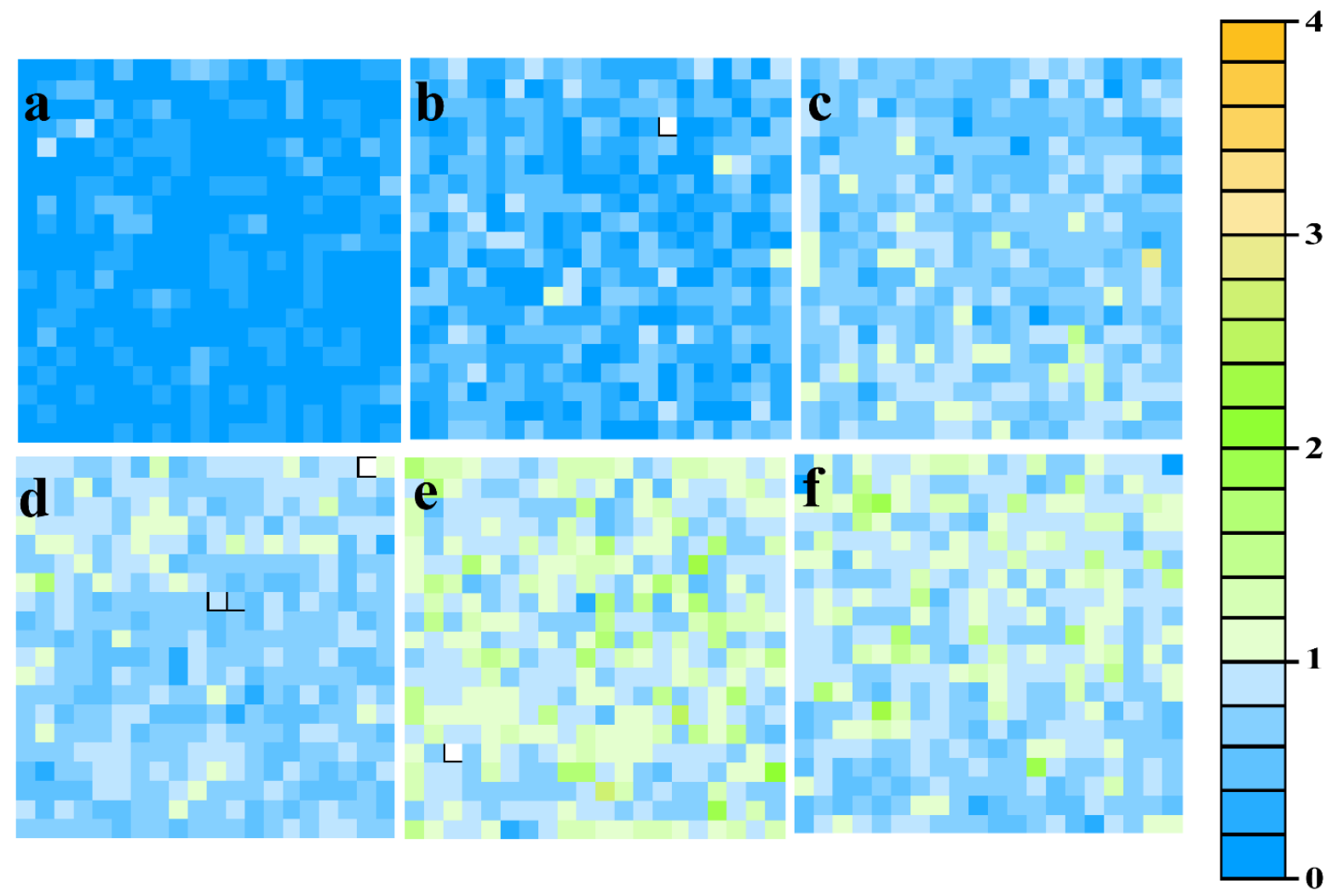

Figure 7. $2 \mathrm{D} / \mathrm{G}$ intensity Raman map over $100 \times 100 \mu \mathrm{m}^{2}$ area of films synthesized at $1055^{\circ} \mathrm{C}$ and $6 \min (a), 12 \min (b), 18 \min (c), 24 \min (d), 30 \min (e)$, and 45min (f) demonstrating bilayer to few layer formation of graphene films produced at $1055^{\circ} \mathrm{C}$ and $30 / 45 \mathrm{~min}$.

Figure 8 a-e demonstrates SAED pattern obtained for the films synthesized at $1055^{\circ} \mathrm{C}$ and different times. The SAED for 6 min (figure 8a) and 12 min (figure 8b) synthesis films show 
intense rings with diffraction spots. These films are hybrid films composed of amorphous and crystalline carbon. However, the films synthesized at $18 \mathrm{~min}$ (figure $8 \mathrm{c}$ ), $24 \mathrm{~min}$ (figure $8 \mathrm{~d}$ ), 30 min (figure 8e), and 45min (figure 8f) reveal only hexagonal diffraction spots indicating the crystalline nature of the graphene films.
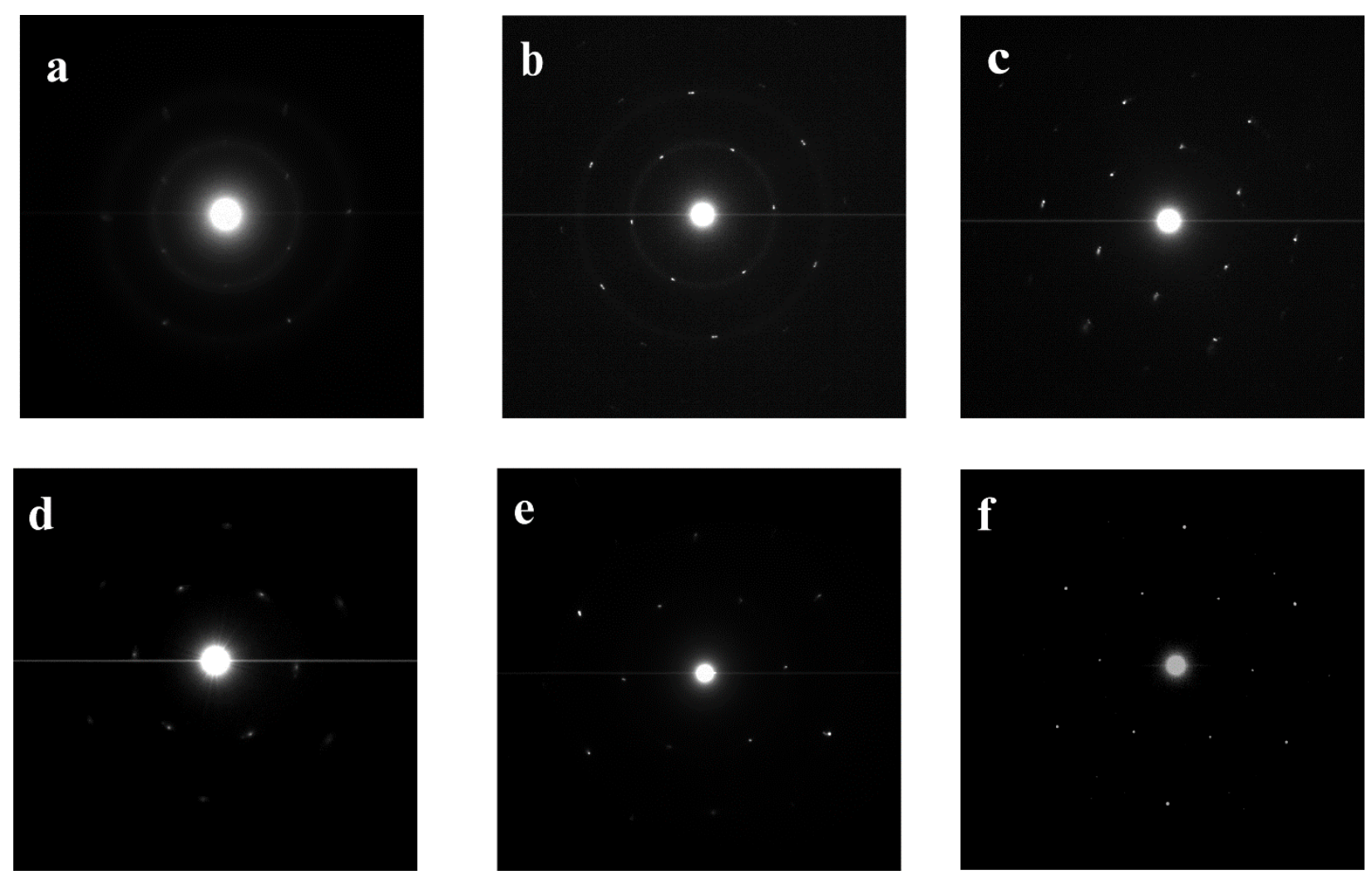

Figure 8. Selected area electron diffraction of films synthesized at $1055^{\circ} \mathrm{C}$ and 6 min (a), 12 $\min (b), 18 \min (c), 24 \min (d), 30 \mathrm{~min}(e)$, and 45min (f). Hybrid films with combination of amorphous rings and diffraction spots is observed for 6 min and 12 min synthesis time; while, crystalline graphene films obtained for longer synthesis times $(18 \mathrm{~min}, 24 \mathrm{~min}, 30 \mathrm{~min}$, and 45min).

Optical microscopy was demonstrated to be a simple and direct technique to visualize graphene domains on the copper substrate [31-33]. Optical detection is a fast approach to 
observe the development of graphene domains and their growth to form graphene films, under various experimental conditions. The domain visualization can be obtained with the assistance of an intrinsic property of the graphene, which is to act as an oxidation barrier [31-33]. The copper substrate when heated in air gets oxidized, whereas the sites with graphene domains remain unaffected. The copper foils with graphene films synthesized at $1055^{\circ} \mathrm{C}$ and different times were placed on a hot plate maintained at $100{ }^{\circ} \mathrm{C}$ for $1 \mathrm{~min}$ to visualize the evolution of the graphene domains. After this exposure, the sites with graphene domains were unaffected, whereas the other region of copper was oxidized. Optical microscopy images (Figure 9) shows the evolution of these graphene domains synthesized at $1055^{\circ} \mathrm{C}$ and different time intervals. The coal derived graphene domains appears to be oval shaped as seen from figure 9. The graphene domain is similar to one of the many different shapes of graphene domain synthesized by $\mathrm{Wu}$ et. al., controlling various process parameters [50]. Graphene domains are hardly visible for $6 \mathrm{~min}$ synthesis times. The graphene domains grow in size as the synthesis time is increased and eventually merge together to form a continuous graphene film covering the surface of the copper foil. 

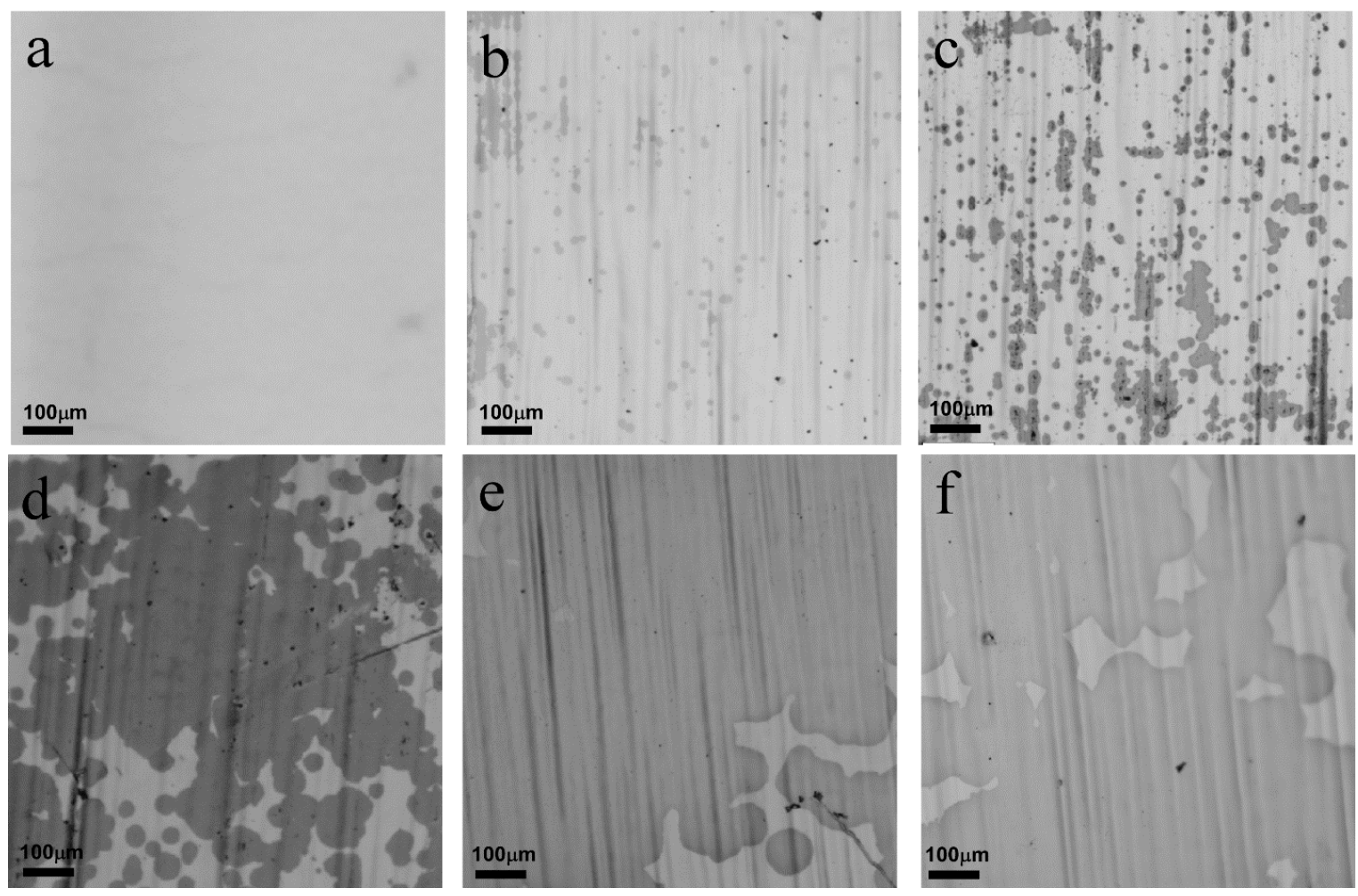

Figure 9. Graphene domains observed utilizing optical microscope. The graphene domains hardly observed for 6 min synthesis (a). With progressive synthesis times, the evolution of graphene domains can be observed for $12 \min ($ b), $18 \min$ (c), and $24 \min (d)$ synthesis. Graphene film is formed by merging of graphene domains for $30 \mathrm{~min}$ (e) and $45 \mathrm{~min}$ (f) synthesis.

Raman spectroscopy was used to verify the graphene domains. Figure 10a shows an isolated oval shaped graphene domain synthesized at $1055^{\circ} \mathrm{C}$ and 30 min. Raman spectra obtained from domain and non-domain region directly on the copper substrate is illustrated in Figure 10b. The Raman spectra of the graphene domain reveals a low intensity D band, G band observed at $1585 \mathrm{~cm}^{-1}$, and the 2D band at $2700 \mathrm{~cm}^{-1}$. The spectra of the non-domain region (figure 10b) only shows the presence of D band and G band, as an indication of an amorphous carbon film surrounding the graphene domain. 

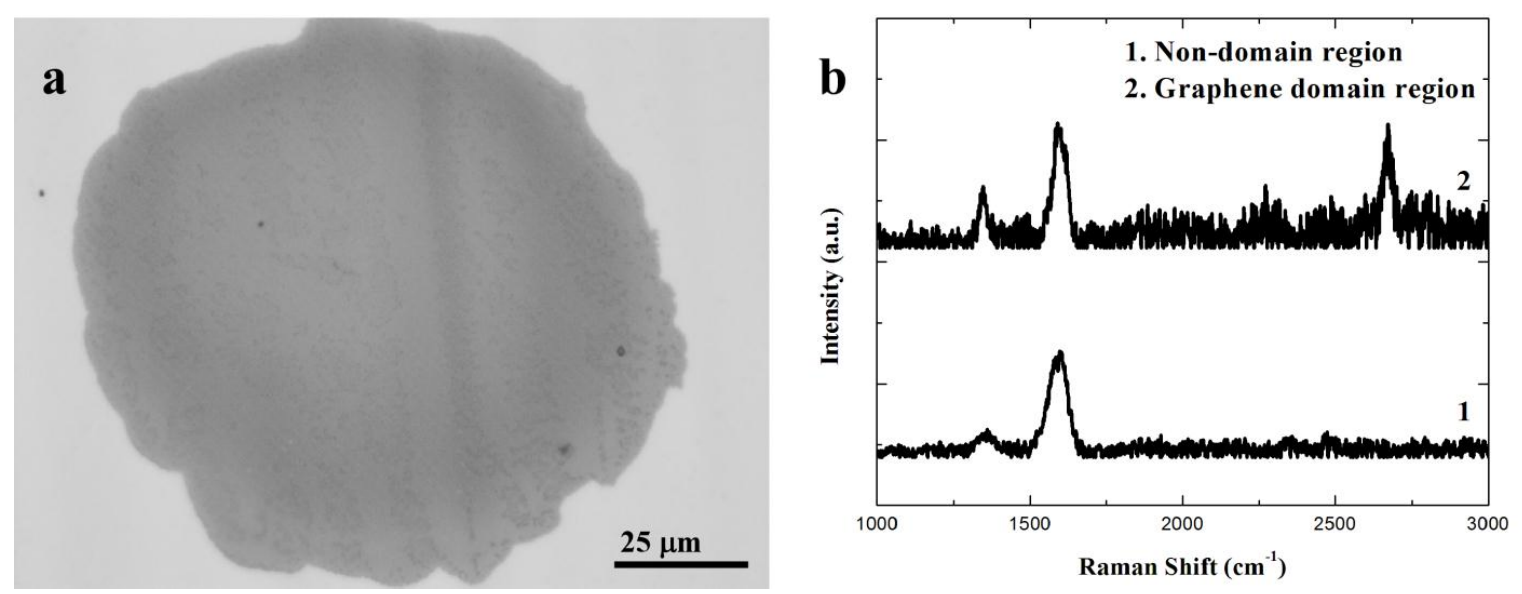

Figure 10. Graphene domain on the copper foil (a) with corresponding Raman measurements (b) indicating the presence of the graphene domain and an amorphous carbon in the background.

The optical microscopy images demonstrated that the domains increase in size and merge together, thus increasing in coverage on the copper substrate. Optical images were also obtained from the replicate samples to determine the uniformity and consistency of the surface area coverage of graphene films as the synthesis time was increased. Figure S5 (see supporting information) illustrates this increase in surface area coverage of graphene domains to form graphene films. The graphene film covers $\sim 95 \%$ surface area of the copper substrate at $30 \mathrm{~min}$ and 45 min synthesis. Previously, it was observed from the Raman mapping that the 2D intensity increases with increase in synthesis time. This behaviour is attributed to an increase in the size of graphene domain with corresponding increase in synthesis time. The optical images were obtained from the replicate samples of films synthesized at different times. The image analysis assisted in validating the increase in domain size as synthesis time increased. Figure S6 (see supporting information) shows that the domain size increases from few micrometers at 12 min synthesis to hundreds of micrometers at $30 \mathrm{~min}$ and $45 \mathrm{~min}$ synthesis.

The mechanism of the graphene growth in this rather simple coal heating approach is 
certainly intriguing. The hydrocarbons released during the pyrolysis of coal act as the precursors for the graphene synthesis. In order to determine these hydrocarbon gases, the Wyodak coal was pyrolyzed at the graphene synthesis conditions and the gases collected in a gas sampling bag using the setup and procedure mentioned in the experimental section. The gases were then analyzed using gas chromatograph. The chromatography analysis reveals the following gaseous products from the coal pyrolysis at the graphene synthesis conditions: Hydrocarbon gases methane, ethane, ethene, propane, and propene, apart from carbon dioxide and carbon monoxide. The hydrocarbon gases (methane, ethane, ethene, propane, and propene) lead to the formation of active carbon species, thus acting as an indirect carbon source for the growth of graphene films.

Thermogravimetric analysis (TGA) on coal was performed utilizing SDT600 TGA (TA instrument) with argon as a carrier gas. $1055{ }^{\circ} \mathrm{C}$ was selected as target temperature under isothermal conditions (30 min pyrolysis time) in order to mimic the synthesis conditions of graphene film. Figure S7 (see supporting information) shows the TGA curve (weight loss $\% \mathrm{v} / \mathrm{s}$ time), which includes the weight loss occurred during the ramp process as well. Majority weight loss occurs within 6 min during the ramp to $1055^{\circ} \mathrm{C}$ demonstrating that all the bulk gases are released within the 6 min of the ramp process. This indicates that during the graphene synthesis process $\left(1055{ }^{\circ} \mathrm{C}\right)$ the coal when exposed to flash pyrolysis will release bulk gases within the first 6 min. According to the TGA there is no other gases coming out of the coal even with further increase in pyrolysis time after the ramp step.

Based on these results from the Raman spectroscopy/mapping, TEM SAED, and optical microscopy, we propose a growth mechanism of coal derived graphene films as demonstrated in the following schematic figure 11 .

1. Carbons atoms from the various hydrocarbon gases released during coal pyrolysis undergo 
copper catalyzed adsorption $[21,23,51]$.

2. This is followed by catalytic dissociation and desorption to form an amorphous carbon film on the copper substrate within the first few minutes of the synthesis.

3. As time progresses, the hydrogen catalyzed dehydrogenation and graphitization of the underlying amorphous carbon occurs to form graphene domains.

4. With further increase in time, the graphene domains grow in size and merge together to form a continuous graphene film on the substrate of copper [21, 23].

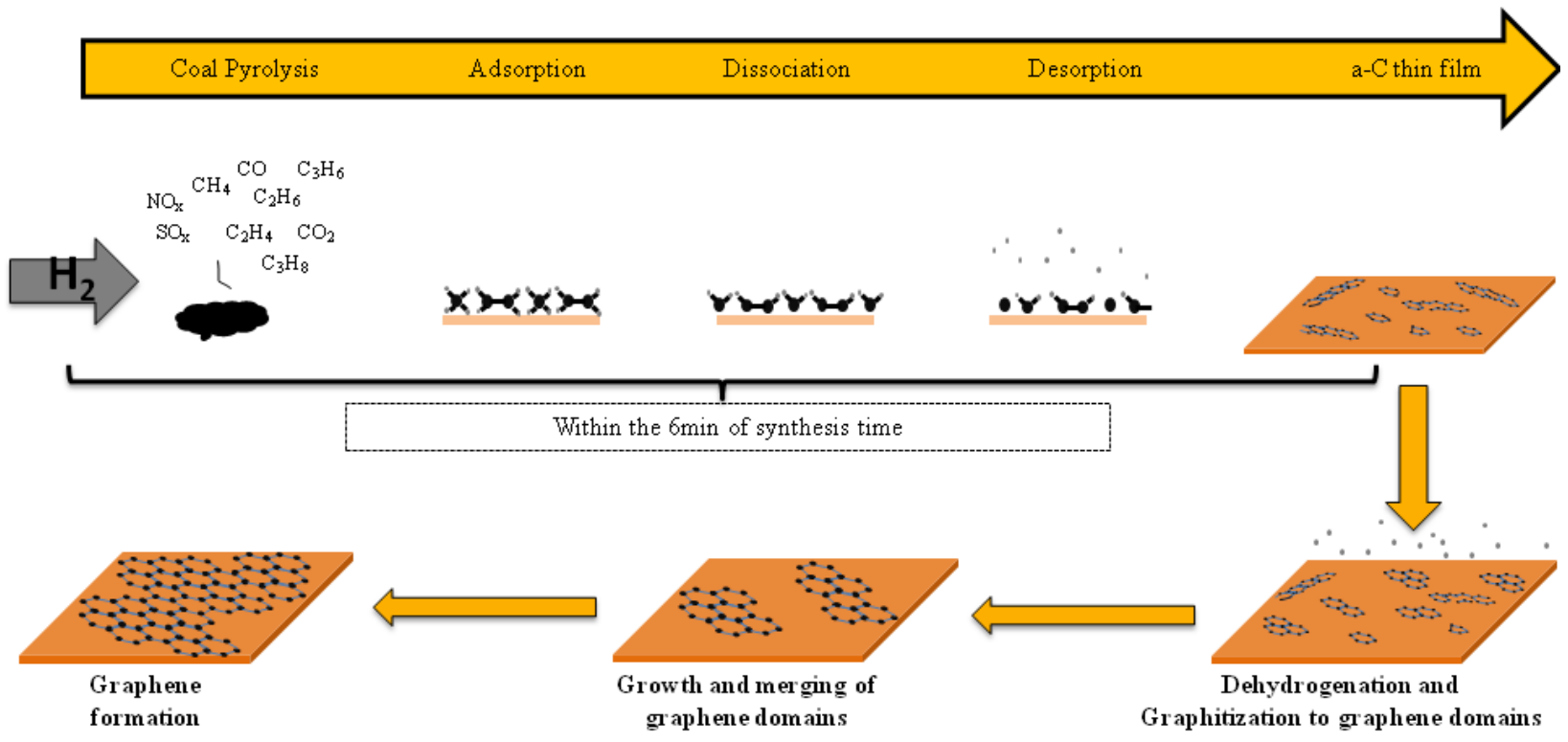

Figure 11. Schematic of growth mechanism of coal derived graphene films showing the formation of amorphous film followed by hydrogen catalyzed graphitization to form graphene domains. As time progresses, the graphene domains grow in size and merge together forming a continuous graphene film on the copper substrate.

Hydrogen also plays a key role for the synthesis of graphene on metals with low solubility of carbon and has been investigated [21, 46]. It has been described as hydrogen induced graphitization/crystallization of the carbon layer on the copper foil to form graphene [21, 
$46,52]$. We believe that in the present work as the synthesis proceeds with time, hydrogen graphitizes the underlying hybrid carbon film produced within the first $6 \mathrm{~min}$ of the growth process to form graphene domains. In order to confirm the hydrogen-induced graphitization, synthesis was performed at the same conditions $\left(1055^{\circ} \mathrm{C}\right.$ and $\left.30 \mathrm{~min}\right)$ as graphene growth, except replacing hydrogen with argon. A continuous carbon film was obtained in the absence of hydrogen at the graphene synthesis conditions. Figure S8 (see supporting information) shows the Raman spectrum of the carbon film revealing the presence of broad D band and G band. However, no 2D band was observed, thus validating the copper assisted growth of a-C films and that copper does not induce crystallization as previously confirmed by various studies [46, 53, $54]$.

The results prove that coal derived graphene growth is not just a consequence of copper catalyzed self-limiting growth and carbon saturation, but it also involves hydrogen induced graphitization of the carbon films.

\section{Conclusion}

Large area and uniform graphene films were obtained utilizing coal as solid carbon source via chemical vapor deposition. The growth mechanism was investigated by implementing Raman spectroscopy/mapping, TEM/SAED, optical microscopy, and gas chromatography. The results show coal pyrolysis release hydrocarbon gases, which act as indirect precursor. The carbon species from the hydrocarbon gases adsorb on the copper to undergo copper catalyzed reaction to form hybrid carbon film. This is followed by graphitization of carbon film to form graphene domains with the aid of hydrogen, eventually leading to formation of graphene films. 


\section{Acknowledgements}

The authors would like to thank for the financial support from the Center for Electrochemical Engineering Research (CEER) at Ohio University, the Ohio Department of Development Office of Energy (Ohio Coal Demonstration and Pilot Program) Grant \# OOECDO-D-13-23, the National Science Foundation through the Major Research Instrumentation Grant \# CBET-1126350, and the W. M. Keck Foundation. The authors would also like to thank Dr. KB Lee from The Sustainable Energy and Advanced Materials (SEAM) laboratory at Ohio University for allowing access to Gas Chromatography and his graduate students Ryan Tschannen, Aaron Gonzales, and Gregory Horne for their assistance. The authors also acknowledge Dr. Mark Singer from the Institute of Corrosion and Multiphase Technology (ICMT) at Ohio University for allowing access to the Infinite Focus Microscope.

\section{References:}

1. Wang X, Zhi L, Mullen K. Transparent, conductive graphene electrodes for dyesensitized solar cells. Nano Lett. 2007; 8(1): 323-27.

2. Westervelt RM. Graphene nanoelectronics. Science 2008; 320(5874): 324-25.

3. Zhu Y, Murali S, Cai W, Li X, Suk JW, Potts JR, et al. Graphene and graphene oxide: Synthesis, properties, and applications. Adv. Mater. 2010; 22(35): 3906-24.

4. Allen MJ, Tung VC, Kaner RB. Honeycomb carbon: A review of graphene. Chem. Rev. 2009; 110(1): 132-45.

5. Liang M, Zhi L. Graphene-based electrode materials for rechargeable lithium batteries. $J$. Mater. Chem. 2009; 19(33): 5871-78.

6. Qu L, Liu Y, Baek J-B, Dai L. Nitrogen-doped graphene as efficient metal-free electrocatalyst for oxygen reduction in fuel cells. ACS Nano 2010; 4(3): 1321-26. 
7. Stoller MD, Park S, Zhu Y, An J, Ruoff RS. Graphene-based ultracapacitors. Nano Lett. 2008; 8(10): 3498-502.

8. Yoo E, Kim J, Hosono E, Zhou H-S, Kudo T, Honma I. Large reversible Li storage of graphene nanosheet families for use in rechargeable lithium ion batteries. Nano Lett. 2008; 8(8): 2277-82.

9. Cai W, Zhu Y, Li X, Piner RD, Ruoff RS. Large area few-layer graphene/graphite films as transparent thin conducting electrodes. Appl. Phys. Lett. 2009; 95(12): 123115-3.

10. Kim KS, Zhao Y, Jang H, Lee SY, Kim JM, Kim KS, et al. Large-scale pattern growth of graphene films for stretchable transparent electrodes. Nature 2009; 457(7230): 706-10.

11. Reina A, Jia X, Ho J, Nezich D, Son H, Bulovic V, et al. Large area, few-layer graphene films on arbitrary substrates by chemical vapor deposition. Nano Lett. 2008; 9(1): 30-35.

12. Li X, Cai W, An J, Kim S, Nah J, Yang D, et al. Large-area synthesis of high-quality and uniform graphene films on copper foils. Science 2009; 324(5932): 1312-14.

13. Li Z, Wu P, Wang C, Fan X, Zhang W, Zhai X, et al. Low-temperature growth of graphene by chemical vapor deposition using solid and liquid carbon sources. ACS Nano 2011; 5(4): 3385-90.

14. Sun Z, Yan Z, Yao J, Beitler E, Zhu Y, Tour JM. Growth of graphene from solid carbon sources. Nature 2010; 468(7323): 549-52.

15. Guermoune A, Chari T, Popescu F, Sabri SS, Guillemette J, Skulason HS, et al. Chemical vapor deposition synthesis of graphene on copper with methanol, ethanol, and propanol precursors. Carbon 2011; 49(13): 4204-10. 
16. Primo A, Atienzar P, Sanchez E, Delgado JM, Garcia H. From biomass wastes to largearea, high-quality, N-doped graphene: Catalyst-free carbonization of chitosan coatings on arbitrary substrates. Chem. Commun. 2012; 48(74): 9254-56.

17. Ruan G, Sun Z, Peng Z, Tour JM. Growth of graphene from food, insects, and waste. ACS Nano 2011; 5(9): 7601-07.

18. Vijapur SH, Wang D, Botte GG. The growth of transparent amorphous carbon thin films from coal. Carbon 2013; 54: 22-28.

19. Vijapur SH, Wang D, Botte GG. Raw coal derived large area and transparent graphene films. ECS Solid State Lett. 2013; 2(7): M45-M47.

20. Wang D, Vijapur SH, Botte GG. Coal char derived few-layer graphene anodes for lithium ion batteries. Photonics 2014; 1(3): 251-59.

21. Kim H, Mattevi C, Calvo MR, Oberg JC, Artiglia L, Agnoli S, et al. Activation energy paths for graphene nucleation and growth on $\mathrm{Cu}$. ACS Nano 2012; 6(4): 3614-23.

22. Li X, Cai W, Colombo L, Ruoff RS. Evolution of graphene growth on $\mathrm{Ni}$ and $\mathrm{Cu}$ by carbon isotope labeling. Nano Lett. 2009; 9(12): 4268-72.

23. Celebi K, Cole MT, Choi JW, Wyczisk F, Legagneux P, Rupesinghe N, et al. Evolutionary kinetics of graphene formation on copper. Nano Lett. 2013; 13(3): 967-74.

24. Li X, Magnuson CW, Venugopal A, An J, Suk JW, Han B, et al. Graphene films with large domain size by a two-step chemical vapor deposition process. Nano Lett. 2010; 10(11): 4328-34.

25. Robertson AW, Warner JH. Hexagonal single crystal domains of few-layer graphene on copper foils. Nano Lett. 2011; 11(3): 1182-89. 
26. Vlassiouk I, Regmi M, Fulvio P, Dai S, Datskos P, Eres G, et al. Role of hydrogen in chemical vapor deposition growth of large single-crystal graphene. ACS Nano 2011; 5(7): 6069-76.

27. Zhang J, Hu P, Wang X, Wang Z. Structural evolution and growth mechanism of graphene domains on copper foil by ambient pressure chemical vapor deposition. Chem. Phys. Lett. 2012; 536: 123-28.

28. Bhaviripudi S, Jia X, Dresselhaus MS, Kong J. Role of kinetic factors in chemical vapor deposition synthesis of uniform large area graphene using copper catalyst. Nano Lett. 2010; 10(10): 4128-33.

29. Lee S, Lee K, Zhong Z. Wafer scale homogeneous bilayer graphene films by chemical vapor deposition. Nano Lett. 2010; 10(11): 4702-07.

30. Liu W, Li H, Xu C, Khatami Y, Banerjee K. Synthesis of high-quality monolayer and bilayer graphene on copper using chemical vapor deposition. Carbon 2011; 49(13): 412230.

31. Jia C, Jiang J, Gan L, Guo X. Direct optical characterization of graphene growth and domains on growth substrates. Sci. Rep. 2012; 2.

32. Wang H, Wang G, Bao P, Yang S, Zhu W, Xie X, et al. Controllable synthesis of submillimeter single-crystal monolayer graphene domains on copper foils by suppressing nucleation. J. Am. Chem. Soc. 2012; 134(8): 3627-30.

33. Zhang Y, Chen Z, Wang B, Wu Y, Jin Z, Liu X, et al. Controllable growth of millimetersize graphene domains on Cu foil. Mater. Lett. 2013; 96: 149-51.

34. Ni Z, Wang Y, Yu T, Shen Z. Raman spectroscopy and imaging of graphene. Nano Res. 2008; 1(4): 273-91. 
35. Ferrari AC, Meyer JC, Scardaci V, Casiraghi C, Lazzeri M, Mauri F, et al. Raman spectrum of graphene and graphene layers. Phys. Rev. Lett. 2006; 97(18): 187401-4.

36. Yao Y, Li Z, Lin Z, Moon K-S, Agar J, Wong C. Controlled growth of multilayer, fewlayer, and single-layer graphene on metal substrates. J. Phys. Chem. C 2011; 115(13): $5232-38$.

37. Wassei JK, Mecklenburg M, Torres JA, Fowler JD, Regan B, Kaner RB, et al. Chemical vapor deposition of graphene on copper from methane, ethane and propane: Evidence for bilayer selectivity. Small 2012; 8(9): 1415-22.

38. Ferrari AC. Raman spectroscopy of graphene and graphite: Disorder, electron-phonon coupling, doping and nonadiabatic effects. Solid State Commun. 2007; 143(1-2): 47-57.

39. Gao L, Ren W, Zhao J, Ma L-P, Chen Z, Cheng H-M. Efficient growth of high-quality graphene films on $\mathrm{Cu}$ foils by ambient pressure chemical vapor deposition. Appl. Phys. Lett. 2010; 97(18): 183109-11.

40. Tiwari RN, Ishihara M, Tiwari JN, Yoshimura M. Synthesis of graphene film from fullerene rods. Chem. Commun. 2012; 48(24): 3003-05.

41. Potgieter-Vermaak S, Maledi N, Wagner N, Van Heerden JHP, Van Grieken R, Potgieter JH. Raman spectroscopy for the analysis of coal: A review. J. Raman Spectrosc. 2011; 42(2): 123-29.

42. Veres M, Füle M, Toth S, Koos M, Pocsik I. Surface enhanced raman scattering (SERS) investigation of amorphous carbon. Diam. relat. mater. 2004; 13(4): 1412-15.

43. Hawaldar R, Merino P, Correia M, Bdikin I, Grácio J, Méndez J, et al. Large-area highthroughput synthesis of monolayer graphene sheet by hot filament thermal chemical vapor deposition. Sci. rep. 2012; 2: 682. 
44. Wang X, You H, Liu F, Li M, Wan L, Li S, et al. Large-scale synthesis of few-layered graphene using CVD. Chem. Vap. Deposition 2009; 15(1-3): 53-56.

45. Yang F, Liu Y, Wu W, Chen W, Gao L, Sun J. A facile method to observe graphene growth on copper foil. Nanotechnology 2012; 23(47): 475705-13.

46. Ji H, Hao Y, Ren Y, Charlton M, Lee WH, Wu Q, et al. Graphene growth using a solid carbon feedstock and hydrogen. ACS Nano 2011; 5(9): 7656-61.

47. Kumar A, Voevodin A, Zemlyanov D, Zakharov D, Fisher TS. Rapid synthesis of fewlayer graphene over $\mathrm{Cu}$ foil. Carbon 2012; 50(4): 1546-53.

48. John R, Ashokreddy A, Vijayan C, Pradeep T. Single-and few-layer graphene growth on stainless steel substrates by direct thermal chemical vapor deposition. Nanotechnology 2011; 22(16): 165701-7.

49. Cui T, Lv R, Huang Z-H, Zhu H, Jia Y, Chen S, et al. Low-temperature synthesis of multilayer graphene/amorphous carbon hybrid films and their potential application in solar cells. Nanoscale Res Lett 2012; 7(1): 1-7.

50. Wu B, Geng D, Xu Z, Guo Y, Huang L, Xue Y, et al. Self-organized graphene crystal patterns. NPG Asia Mater 2013; 5: e36.

51. Mehdipour H, Ostrikov K. Kinetics of low-pressure, low-temperature graphene growth: Toward single-layer, single-crystalline structure. ACS nano 2012; 6(11): 10276-86.

52. Hu B, Ago H, Orofeo CM, Ogawa Y, Tsuji M. On the nucleation of graphene by chemical vapor deposition. New J. Chem. 2012; 36(1): 73-77.

53. Rodríguez-Manzo JA, Pham-Huu C, Banhart F. Graphene growth by a metal-catalyzed solid-state transformation of amorphous carbon. ACS nano 2011; 5(2): 1529-34. 
54. Zheng M, Takei K, Hsia B, Fang H, Zhang X, Ferralis N, et al. Metal-catalyzed crystallization of amorphous carbon to graphene. Appl. Phys. Lett. 2010; 96(6): 06311012. 


\section{Coal}

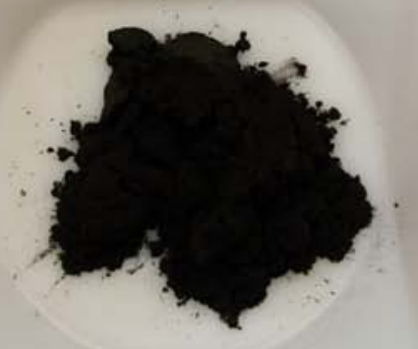

CVD

$500 \mathrm{~nm}$ 